\title{
Paideuma concreto y cómo dar dimensiones al poema
}

\author{
Óscar Humberto Mejía-Blanco*
}

\footnotetext{
Magíster en Literatura. Profesor asociado, Universidad Industrial de Santander, Bucaramanga, Colombia. Correo electrónico:

orestesatrida@hotmail.com
}

Recibido: 12 de mayo del 2015

Aprobado: 3 de agosto del 2015

Cómo citar este artículo: Mejía-Blanco,

Óscar Humberto. "Paideuma concreto y cómo dar dimensiones al poema". Rastros Rostros 17.31 (2015): 151-155. Impreso. doi: http:// dx.doi.org/10.16925/ra.v17i31.1099

\section{Resumen}

Propósito: este artículo busca dar cuenta de las preocupaciones renovadoras del lenguaje en la poesía concreta brasileña, ahondando en el concepto paideuma. Temas: a fin de cumplir este propósito, se hace aquí una revisión y explicación de este término, recurriendo a los planteamientos realizados por los hermanos Augusto y Haroldo de Campos y Decio Pignatari en Olho por olho a olho un (manifiesto). Desarrollo: asimismo, se explora la poesía de los autores seleccionados y establecidos por este trío como precursores de las nuevas formas, temas y modos de expresión de este programa artístico y literario latinoamericano. Conclusiones: así, la poesía concreta brasileña entraña un cambio en el uso del lenguaje literario, pues problematiza el modo en que se realiza la expresión de los contenidos a través de algunos procedimientos estilísticos, dictados desde el influyente acervo poético de autores como Joyce, E. E. Cummings y Ezra Pound.

Palabras clave: idea prismática, objeto del lenguaje, paideuma, renovación, verbi-voco-visual. 


\title{
Concrete paideuma and how to dimension the poem
}

\begin{abstract}
Purpose: this article seeks to account for the renewing concerns of language in the Brazilian concrete poetry, delving into the concept of paideuma. Topics: to fulfill this purpose, a review and explanation of the term is included herein, drawing on the proposals made by brothers Augusto and Haroldo de Campos and Decio Pignatari in Olho por olho a olho un (manifiesto). Development: additionally, the poetry of the authors selected and considered by this trio as precursors of new forms, themes, and modes of expression of this Latin American artistic and literary program is explored. Conclusions: thus, the Brazilian concrete poetry involves a change in the use of literary language as it questions the manner in which contents are expressed through some stylistic procedures, dictated from the influential poetic heritage of writers like Joyce, E. E. Cummings and Ezra Pound.
\end{abstract}

Keywords: prismatic idea, purpose of language, paideuma, renovation, verbivoco-visual.

\section{Paideuma concreto e como dar dimensões ao poema}

\section{Resumo}

Propósito: este artigo busca refletir as preocupações renovadoras da linguagem na poesia concreta brasileira, aprofundando no conceito paideuma. Temas: para cumprir esse objetivo, é feita uma revisão e explicação deste termo, recorrendo as colocações feitas pelos irmãos Augusto e Haroldo de Campos e Décio Pignatari em Olho por olho a olho um (manifesto). Desenvolvimento: igualmente, explora-se a poesia dos autores selecionados e estabelecidos por este trio como precursores das novas formas, temas e modos de expressão deste programa artístico e literário latino-americano. Conclusões: assim, a poesia concreta brasileira possui uma mudança no uso da linguagem literária, já que problematiza o modo em que se realiza a expressão dos conteúdos através de alguns procedimentos estilísticos, ditados desde o influente acervo poético de autores como Joyce, E. E. Cummings e Ezra Pound.

Palavras-chave: ideia prismática, objeto da linguagem, paideuma, renovação, verbivocovisual. 


\section{Introducción}

En 1956 se lleva a cabo la exposición de arte concreto, en Brasil. En esta se dan a conocer los primeros poemas concretos latinomaericanos, los cuales sientan las bases de uno de los movimientos vanguardistas más destacados de la segunda mitad del siglo $\mathrm{xx}$ en el continente. Un poco antes, en 1952, Haroldo y Augusto de Campos - junto a Decio Pignatarifundan ${ }^{1}$ el famoso grupo Noigandres. Para entonces, la poesía concreta solo es un embrión que empieza a constituirse como movimiento poético y cultural, en cuya ensencia fluctúa una de las preocupaciones de los poetas modernos: la crisis del estaticismo en el uso del del lenguaje. Fieles seguidores del pensamiento de Maiakovski, según el cual sin forma revolucionaria no hay arte revolucionario, en la década de 1950 los poetas brasileños no solo tranforman el panorama de la poesía de su país, sino también enriquecen la literatura contemporánea desde posiciones de radicalidad estética. Para ellos, la poesía concreta se define como una responsabilidad integral frente al lenguaje; en su manifiesto concretista, los tres poetas de San Pablo divulgan los rasgos más destacados de su proyecto creativo. Así, este movimiento poético es producto de la evolución científica y crítica de las formas, ya que con esta poesía se da por cerrada la estructura biplanar del signo lingüístico - forma y contenido - para dar paso al dinamismo que les ofrece la dimensión de la página, el juego de los sonidos en la lectura y las diferentes tipografías de la escritura. No obstante, hay que aclarar que este programa de temas e intenciones no se plantea de la nada; nace, precisamente, de la consideración y establecimiento de un paideuma, grupo de poetas y poéticas anteriores que fungen como un entramado de ideas y preceptos que influyen en la conformación de un nuevo producto cultural.

Este término es readaptado por el poeta Ezra Pound en Guide to Kulchur. An iconoclastic revision of culture (1970), y se aproxima a definirlo como un conjunto de ideas usadas otrora por un grupo humano particular, en un período determinado (Vera 2). Bajo

Haroldo de Campos (1929-2003). Traductor, crítico y poeta brasileño. Gestor, con su hermano Augusto y Decio Pignatari, del movimiento de poesía concreta. Augusto de Campos (1931). Es uno de los exponentes de la poesía concreta. Su obra también abarca la creación poética, el ensayo y la traducción. Decio Pignatari (19272012). Poeta, ensayista, traductor, cuentista, dramaturgo, publicista y profesor. En 1952, edita la revista-libro Noigandres, con los hermanos De Campos. esa perspectiva, para Augusto y Haroldo de Campos y Decio Pignatari era necesario construir un paideuma propio, una suerte de tejido poético guía con el cual alimentar las directrices particulares de su movimiento artístico, esto con el fin de determinar los propósitos de su programa literario y manifiesto creativo.

En Olho por olho a olho un (manifiesto), Haroldo de Campos presenta el propósito radical de la nueva poética que regirá el trasegar de la poesía concreta; se pretende crear un arte que no represente al objeto, sino más bien que lo "presentifique" (De Campos et al. 73). De entrada, esta afirmación mueve los cimientos de la poesía tradicional. Esta directriz pone en evidencia la ineficacia del modelo biplanar de representación del signo lingüístico de Saussure, constituido por forma y contenido, e invita a explorar nuevas formas expresivas que den dimensiones al poema, que superen esa dualidad. Si el manifiesto concreto triunfa en este sentido, ya no serían funcionales las formas decimonónicas y tradicionales en el poema: la métrica, la sintaxis, la ilación narrativa. En cambio, serían necesarias estrategias, las cuales resulten del establecimiento y apropiación de rasgos pertinentes y diferenciadores de otras corrientes literarias, a fin de desautomatizarlas, actualizarlas y comunicar a través de ellas la esencia o contenido, en un horizonte inédito en otros modelos de expresión poética: la poesía concreta. "Presentificar" es sustraer al poema de su biplanaridad y complejizar su escritura, a fin de concederle forma pero también un plano oral y visual.

\section{Metodología}

El concretismo poético brasileño y su continuum de rasgos pertinentes, paideuma, se componen de los aportes de cuatro autores: Stéphane Mallarmé, Joyce, E.E. Cummings y Ezra Pound. A fin de determinar el arte poética concreta desde el paideuma de la poesía concreta, basta con rastrear el registro de los poetas precursores que lo conforman. En este son evidentes las estéticas, así como aspectos que ayudan a establecer una línea transversal entre los autores integrantes. Respecto de las problemáticas planteadas con relación al lenguaje, en los diferentes manifiestos de los hermanos De Campos puede interpretarse que en su grupo precursor hubo una predisposición y apertura hacia otras culturas y métodos de composición. Tal es el caso del uso de la idea prismática y la concepción de la página en blanco como pentagrama, planteamiento de Mallarmé (De Campos et al. 178) 
que considera a la página como un terreno en blanco el cual puede ser empleado por el poeta para dotar al poema de sentido(s), de una manera muy diferente a la de la poesía tradicional. Asimismo, a la idea de lo prismático se une el concepto de escritura ideográfica y recursos de condensación (De Campos et al. 22). Lo prismático, ya adivinado en Mallarmé, y lo ideográfico también atraviesan la estilística de Ezra Pound y, en cierta medida, de E. E. Cummings, poetas que se ocuparon también de usar dinámicamente el espacio de la página y asimismo el de las tipografías, estrategias que permiten un margen amplio de sentido en el cual las ideas fluyen, a fin de escapar del espacio reducido y la inflexibilidad que ofrecen la sintaxis y la lógica de la métrica (De Campos et al. 114).

\section{Hallazgos}

Recapitulando, la poesía concreta brasilera es fiel a su paideuma. Renueva las posibilidades de sentido de la expresión, bien sea en el plano de las ideas, de la expresión, de la tipografía o del papel. Repotenciar y redimensionar, así como agotar e, incluso, declarar limitada la concepción del signo lingüístico y su función de representar un objeto, su imagen acústica y su contenido, es el propósito de los concretistas. En su momento, el paideuma (De Campos et al. 74) recurrió a nuevas metodologías: apelaron a las fibras de los sentidos de manera simultánea (como ya se mencionó en apartados anteriores, ya no era suficiente que el poeta tratara de representar al objeto, "decir" esto o aquello sobre este en una secuencia narrativa de inicio, nudo y desenlace). El propósito, más bien, era evocarlo al presente al momento de su lectura con la palabra, dimensionarlo, dotarlo de capas, de relieve, como sucede en el ejercicio de trasladar un boceto a terceras dimensiones, en maquetas o sólidos para dejar a un lado - como ya se ha insistido- las viejas estructuras de la métrica y la sintaxis. A continuación, se hace un breve análisis de estos planteamientos en uno de los poetas que componen el paideuma concreto, Ezra Pound.

\section{Canto cxx}

I have tried to write Paradise

Do not move

Let the wind speak that is paradise.

Let the Gods forgive what I have made

\section{Let those I love try to forgive what I have made. (Pound)}

En el primer verso "I have tried to write Paradise", Pound no escribe la preposición sobre, o alguna otra particula conectora o sustantivo que dé la noción de la presencia temática de paradise como tópico de la escritura de la escritura poética, sino que introduce el término como un complemento de objeto directo. El paraíso es lo que se va a escribir, y esto provoca un efecto rápido y certero en la imagen que el lector configura. Con relación a los imperativos de silencio y el subsiguiente llamado de atención, "Do not move/ Let the wind speak", se intuye la cercanía a la cosmogonía oriental, a la contemplación y enunciación de una imagen condesadora a manera de haikú. Ello termina en la revelación "that is paradise". En las líneas siguientes, la voz lírica contemplativa y aislada manifiesta un sentimiento de culpa; las imágenes son arrastradas por el viento de la redención.

Por otro lado, ya en E.E. Cummings, se objetivan los siguientes rasgos distintivos:

\section{Señora del silencio...}

Señora del Silencio
de la dulce jaula de
tu cuerpo
se alzó en la sensitiva
noche
un
pájaro veloz
(tierna sobre
el prodigioso rostro de lo oscuro
tu
voz
perfume
escoltando de pronto
con soleados
pies
la punzante belleza de la aurora).
(Cummings)

En este poema se observa un procedimiento similar al usado por Pound en Canto cxx, en el cual presenta al viento, pide silencio, y ese viento es el paraíso. Aquí, el pájaro veloz es la voz, dos conceptos superpuestos: voz/pájaro; en Pound: viento/paraíso. 
Estos procedimientos preparan la entrada de otra noción de suma importancia: lo verbi-voco-visual, concepto aunado al de ideograma (desarrollar la idea en imágenes y símbolos y reducir la literalidad del signo), noción también en armonía con el concepto de "idea prismática" ${ }^{2}$, rescatado de Mallarmé. Si unimos hasta aquí todo lo esbozado, la hoja en blanco como el escenario en que podría ponerse en juego todo, donde todo se difumina, significa y es relieve, de manera que los objetos y sus imágenes se "presentifican" simultáneamente.

Otro referente de peso en el paideuma concreto es Jame Joyce, particularmente con su obra Finnegans Wake (1939). De esta se sustrae el término verbi-voco-visual, que hace referencia a la palabra, el sonido y la imagen, elementos que deben convivir dentro del poema: continente y contenido, tiempo y espacio, todos en un instante o en una palabra, como atomización y dispersión del significado (De Campos et al. 133). En Finnegans Wake, hay una morfología de la palabra afectada; hay injertos de palabras dinámicos y posesos de múltiples significados. Por ejemplo, en el cuarto párrafo del capítulo I, entre muchas otras, se encuentra la palabra pentschanjeuchy, que el diccionario Finnegans Wake and Wiki remite al término panschen (alemán): "to mix $\rightarrow$ water and wine"3; y Punch and Judy Show: "puppet show based on characters from the Italian Commedia dell'arte"4. Según esto, esta palabra estaría compuesta por retazos de otras y tendría, entre muchos, el significado de un personaje dado a la bebida y a la vez a la comedia, al humor, y esto dejando a un lado todas las alusiones que Joyce hace al libro bíblico del Pentateuco, relación que se establece al efectuar la lectura en voz alta de la palabra. Del mismo modo sucede en el verbo watsch (what, wacth, wash), el cual podría tener el sentido de lavar, ver y cuestionarse, todos ellos funcionando al tiempo en una sola palabra, incluso en la dimensión onomatopéyica (el sonido del agua batiéndose contra lo que se lava). Son estos los rasgos triádicos que alimentaron, desde el paideuma, desde el grupo de poetas precursores, los movimientos expresivos y estilísticos de la poesía concreta.

\section{Conclusión}

Todo lo anterior se absorbió - y se expandió- como una suerte de explosión primitiva. El movimiento poético concreto, alimentándose de un paideuma totalmente comprometido con la revolución del lenguaje, con su desautomatización, apunta al paralelismo o simultaneidad de acción de diferentes dimensiones en el poema, relacionadas entre sí: lo verbi-voco-visual. Se pudo demostrar que el paideuma apunta a la no linealidad, que las tres fuerzas del poema concreto apuntarían a un solo punto, pero a la vez a todos los puntos. Eficacia, brevedad y economía. En este orden de ideas, es inevitable considerar el siguiente rumbo de la pesquisa y conocimiento de la poesía concreta que se propuso en este artículo, y es estudiar desde estos hallazgos los poemas concretos de De Campos y Pignatari, con el fin de proponer una guía de lectura aproximativa y de investigación de este fenómeno poético latinoamericano. También será necesario el análisis de la poesía concreta bajo esta perspectiva, con el propósito de observar la herencia lingüística y estilística de los precursores y, de la misma manera, la potenciación, ampliación y desarrollo de sus formas.

\section{Referencias}

De Campos, Augusto et al. "Olho por olho a olho un (manifiesto)". Teoria da poesía concreta, textos críticos y manifiestos, 1950-1960. Cotia, SP: Atelie Editorial, 2006. Impreso.

E. E. Cummings. Señora del silencio. Web A media voz. Web. 16 de febrero de 2012.

Finnegans Wake and Wiki. Pentschanjeuchy. Finnegans Wake. Web. 19 de marzo de 2011.

Pound, Ezra. Canto Cxx. Web Poets.org from the Academy of Americans poets. Web. 16 de febrero de 2012.

Verá Barrios, Tomás. "La Poesía Concreta Brasileña, teorías, poética(s), manifiestos". Todas as letras R 13.2 (2011): 27-43. Web.

2 Llenar el espacio de la página con una imagen poética y esparcirla por los espacios del poema. 